\title{
CENTRAL GIANT CELL GRANULOMA OF THE JAWS AND GIANT CELL TUMOR OF LONG BONES - AN IMMUNOHISTOCHEMICAL COMPARATIVE STUDY
}

\author{
Maria do Socorro ARAGÃ̃ ${ }^{1}$, Marta Rabello PIVA², Cassiano Francisco Weege NONAKA ${ }^{3}$, Roseana de Almeida FREITAS ${ }^{4}$, \\ Lélia Batista de SOUZA ${ }^{4}$, Leão Pereira PINTO ${ }^{4}$
}

\begin{abstract}
1- DDS, MSc, PhD, Professor, Department of Clinic and Social Dentistry, School of Dentistry, Federal University of Paraiba, João Pessoa, PB, Brazil.

2- DDS, MSc, Professor, Department of Oral Pathology, School of Dentistry, Federal University of Sergipe, Aracaju, SE, Brazil.

3- DDS, MSc, Department of Oral Pathology, School of Dentistry, Federal University of Rio Grande do Norte, Natal, RN, Brazil.

4- DDS, MSc, PhD, Professor, Department of Oral Pathology, School of Dentistry, Federal University of Rio Grande do Norte, Natal, RN, Brazil.

Corresponding address: Dr. Leão Pereira Pinto - Faculdade de Odontologia da Universidade Federal do Rio Grande do Norte - Av. Senador Salgado Filho, 1787, Lagoa Nova, 59056-000 - Natal, RN, Brasil - Phone: 5584 3215-4138 - e-mail: 1ppinto@digi.com.br

Received: December 12, 2006 - Modification: May 31, 2007 - Accepted: June 16, 2007
\end{abstract}

\begin{abstract}
O

bjective: This study investigated whether some components of the extracellular matrix and CD68 expression may drive the differences between the central giant cell granuloma (CGCG) of the jaws and giant cell tumor (GCT) of long bones, which present distinct evolution and clinical behavior. Material and Methods: Eight cases of CGCG and 7 cases of GCT were selected and immunohistochemically analyzed to verify the pattern of expression of CD68, tenascin (Tn) and fibronectin (Fn). Results: A large number of the mononuclear cells and multinucleated giant cells CD68+ was observed in both of the studied lesions, indicating histiocyte/ macrophage origin. Seven cases of CGCG of the jaws showed intense staining of Fn, with uniform distribution predominantly. In all 7 cases of GCT of long bones the Fn displayed intense expression, with distribution pattern varying from uniform to reticulate/fibrillar. Six cases of CGCG were intensively stained by Tn, presenting focal expression in half of specimens, and reticulate/ fibrillar pattern of expression in 4 cases. All cases of GCT of the long bones presented intense expression of Tn, uniform distribution, and reticulate/fibrillar pattern of expression in four cases. Conclusions: The immunoexpression of CD68 in mononuclear cells and multinucleated giant cells and staining patterns of Fn and Tn were similar in both entities. These findings indicate that these proteins could not be used to explain the differences between the CGCG of the jaws and GCT of the long bones.
\end{abstract}

Uniterms: Giant cell granuloma; Giant cell tumor; Fibronectins; Tenascin; CD68.

\section{INTRODUCTION}

Central giant cell granuloma of the jaws and giant cell tumor of long bones are well-recognized entities revealing benign nature ${ }^{16}$. Their clinical behavior ${ }^{8,13,29}$, prognostic factors and the histogenesis have been subject of several studies. In spite of that, these questions remain unclear ${ }^{11,16,23,26}$

Morphologic studies performed in order to compare CGCG and GCT features have shown that although most of jaw lesions may be distinguished from tumor of long bones on histological appearance, many jaw lesions display the histological profile of the tumor of long bones. Whitaker and Waldron ${ }^{29}$ (1993) reported that CGCG of the jaws and GCT of long bones could represent the development of a single pathologic process that may be influenced by patient's age, location and other unknown factors. The true GCT of the jaws is rare and local prognosis is considered worse in GCT than in $\mathrm{CGCG}^{8}$.

The biologic behavior of CGCG of the jaws ranges from a quiescent lesion with absence of symptoms, root resorption or cortical perforation, slow growth, and low recurrence rate, to an aggressive pathological process, characterized by pain, rapid growth, root resorption, cortical perforation, and a high recurrence rate $\mathrm{e}^{8,21}$. The GCT of long bones is a rare benign neoplasm, characterized by local aggressiveness, high recurrence rates and metastasis to the lung ${ }^{14,16,21,25}$. The principal characteristic of GCT is the unpredictable biological behavior ${ }^{28}$.

An immunohistochemical study to determine the immunoprofile of the mononuclear cells and proliferative compartment of CGCG of the jaws in clinically aggressive and non-aggressive lesions, using antibodies to CD34, CD68, factor XIIIa, alfa-smooth muscle actin, prolyl 4- 
hydroxylase, Ki-67, and p53 protein, revealed that these lesions are primarily fibroblastic (and myofibroblastic) with macrophages playing a secondary role, and that it is not possible to predict the behavior of the CGCG of the jaws from histologic features, immunophenotypic or proliferation parameters $^{19}$. Other studies have demonstrated immunoreactivity of mononuclear cells and multinucleated cells to CD68 in giant cell lesions, suggesting a histiocyte/ macrophage origin for a subset of cells of these lesions ${ }^{6,16,19,28}$. CD68 is a transmembrane glycoprotein of unknown function, being strongly expressed by human monocytes and tissue macrophages ${ }^{10,20}$.

Several groups of investigators have carried out immunohistochemical studies to observe the immunoreactivity, and distribution pattern of the fibronectin and tenascin in dermatologic diseases ${ }^{22}$, giant cell granulomas ${ }^{5}$, odontogenic cysts ${ }^{18}$, and normal oral mucosa, epithelial dysplasia and fibroepithelial hyperplasia ${ }^{3}$. Fibronectin has several functions, being one of the main cell-matrix ligands ${ }^{2}$. It is found prominently in the matrix of many connective tissues and is more abundant during embryonic development, tissue remodeling ${ }^{4}$ and within a wide variety of basement membranes ${ }^{1}$. The fibronectin arrangement in focal adhesions stimulates the cellular growth by increasing the cell entry into the S-phase of cell cycle ${ }^{9}$. The proliferative activity and newly formed vessels associated to a fibronectin variant support the idea that some types of fibronectin could be important prognosis factors $^{12}$

Tenascin is expressed in epithelial-mesenchymal interactions during embryogenesis and tumorigenesis. This protein has demonstrated significant variation in the distribution and immunoreactivity intensity within individual samples of several lesions ${ }^{17}$ and pathologic processes ${ }^{7}$, being strongly expressed in epithelial malignant tumors ${ }^{24}$.

The purpose of this study was to investigate the CD68 expression in mononuclear and multinucleated giant cells and the pattern of immunoreactivity and distribution of fibronectin and tenascin between CGCG of the jaws and GCT of long bones, in order to analyze if there are differences in the expression of these proteins that could be used to distinguish the studied lesions.

\section{MATERIAL AND METHODS}

Eight cases of CGCG of the jaws were retrieved from the files of the Oral Pathology Discipline of the Federal University of Rio Grande do Norte, School of Dentistry, and 7 cases of GCT of long bones were obtained from the files of the Pathology and Cytology Laboratory of Aracaju - SE. Microscopic slides on each case were reviewed and histologic features of multinucleated giant cells, mononuclear cells and stroma were assessed.

For the immunohistochemical study, $3-\mu \mathrm{m}$ sections were obtained from the formalin-fixed paraffin-embedded surgical specimens of the lesions. Immunohistochemical staining was carried out using the streptavidin-biotin-peroxidase complex (SABC) method. The following antigens were evaluated: CD68 (macrophage-associated monoclonal antibody, KP-1(2) clone, 1:50; Dako, Glostrup, Denmark), incubated at $4{ }^{\circ} \mathrm{C}$ overnight; fibronectin (A-245 clone, 1:600; Dako), incubated at room temperature for $120 \mathrm{~min}$ and tenascin (TN2 clone, 1:50; Dako), incubated at $4^{\circ} \mathrm{C}$ overnight. For the antibodies against fibronectin and tenascin the tissue sections were previously treated with $0.1 \%$ and $0.4 \%$ pepsin respectively, and for the CD68 the antigen retrieval was processed in citric acid in three cycles for 5 minutes (700watts). Diaminobenzidine was used as chromogen.

The immunoreactivity expressed by CD68, fibronectin and tenascin antigen was evaluated in all the cases by light microscopy, using the following parameters: positive $(+)$ and negative (-) staining of the mononuclear cells and multinucleated giant cells for the CD68 antigen, and degrees of staining intensity (intense or weak), distribution (uniform scattered or in focal areas) and expression pattern (fibrillar, reticular and fibrillar/reticular) of the fibronectin and tenascin in the interstitial extracellular matrix and around blood vessels. Two previously calibrated examiners carried out the immunohistochemical evaluation of the specimens.

\section{RESULTS}

\section{CD68}

CD68 positive cells were detected in many mononuclear cells and in the majority of multinucleated giant cells of the CGCG of the jaws (Figure 1) and GCT of long bones (Figure 2) evaluated.

\section{Fibronectin and Tenascin}

The immunostaining results for fibronectin and tenascin in CGCG and GCT are summarized in Tables 1-4, and depicted in Figures 3-6.

\section{DISCUSSION}

Although the origin of the cells present in giant cell lesions has been investigated through histochemistry ${ }^{23}$, ultrastructural ${ }^{19,23}$ and immunohistochemical methods ${ }^{13,23}$, the pathogenesis and nature of these lesions are still unclear.

Whether the CGCG of the jaws and the GCT of long bones are really a single pathologic process is also an unanswered question. As stated by Whitaker and Waldron ${ }^{29}$ (1993), CGCG of the jaws and GCT of long bones could represent the development of a single pathologic process, modified by age of the patient, location, and other unknown factors.

In attempt to clarify whether CGCG and GCT are separate entities or variants of the same disease, Souza, et al. ${ }^{21}$ (1999) performed an immunohistochemical study of the cell cycle related proteins p53, MDM2, Ki-67 and PCNA in samples of both lesions. These authors verified wide expression of MDM2 in CGCG and in GCT and no immunoreactivity to p53 in both lesions. Comparing the proliferative activity 
between lesions, GCT revealed a reduced percentage of Ki67- and PCNA-positive cells. In view of their results, these authors suggest that $\mathrm{p} 53$ inactivation by MDM2 expression may be involved in the pathogenesis of CGCG and GCT.

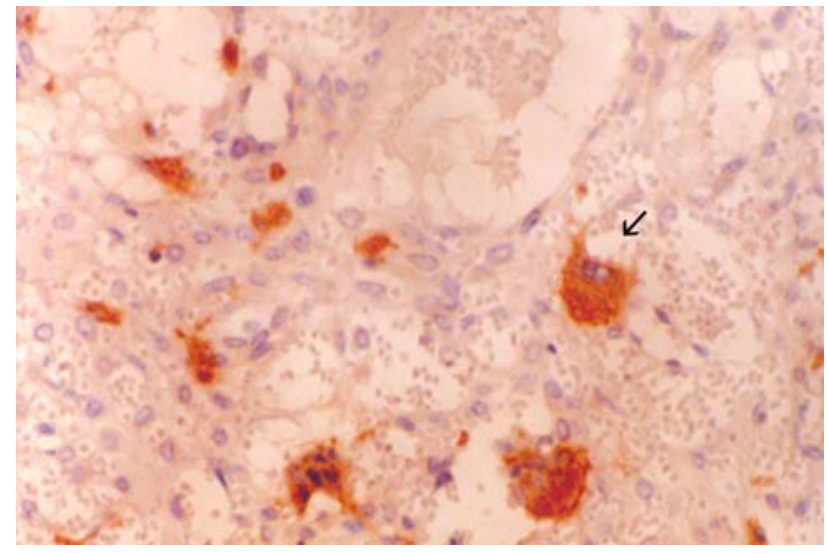

FIGURE 1 - Multinucleated giant cells and individual mononuclear cells CD68 positive in central giant cell granuloma of the jaws (arrow) (SABC - 200x)

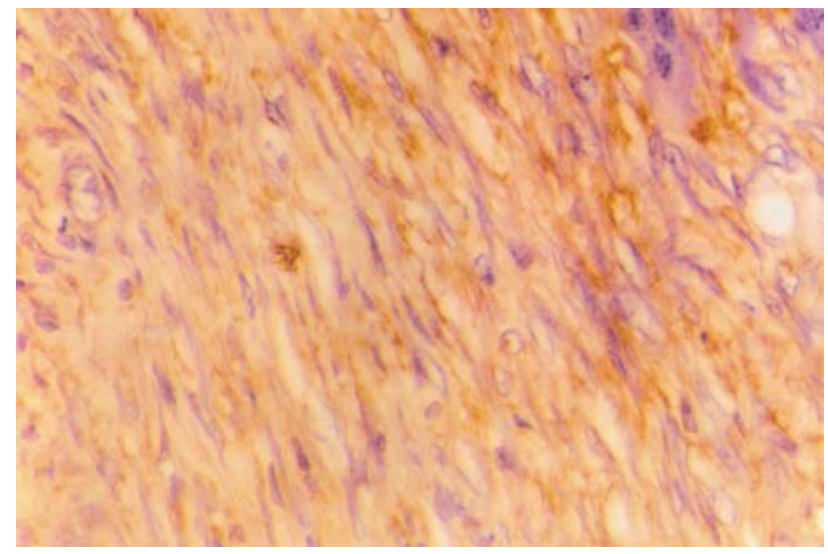

FIGURE 3 - Fibronectin immunoreactivity in central giant cell granuloma of the jaws. Fibrillar organization pattern following the collagen fibers (SABC - 200x)

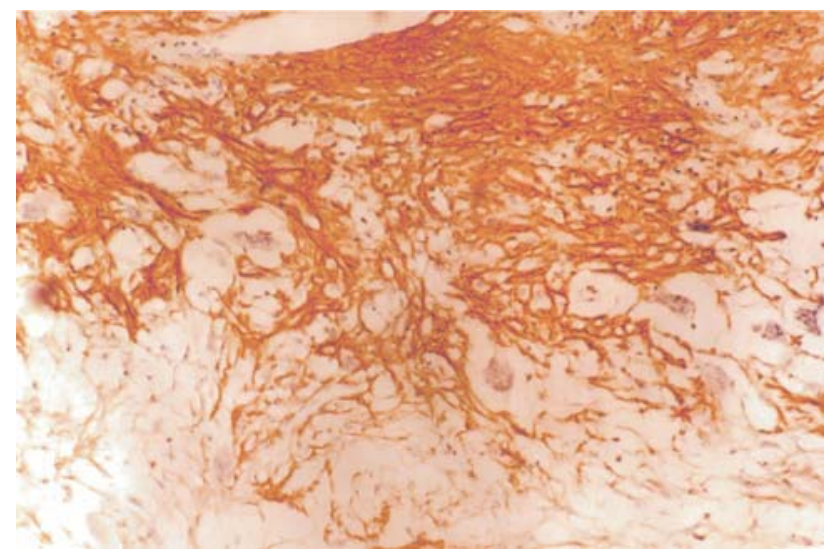

FIGURE 5 - Tenascin immunoreactivity expression in central giant cell granuloma of the jaws. Reticulate/fibrillar organization pattern (SABC - 100x)
In addition, Souza, et al. ${ }^{21}$ (1999) state that the differences observed in proliferative activity do not explain the different biological behavior of CGCG and GCT, as reactive lesions may show increased proliferative activity. The authors

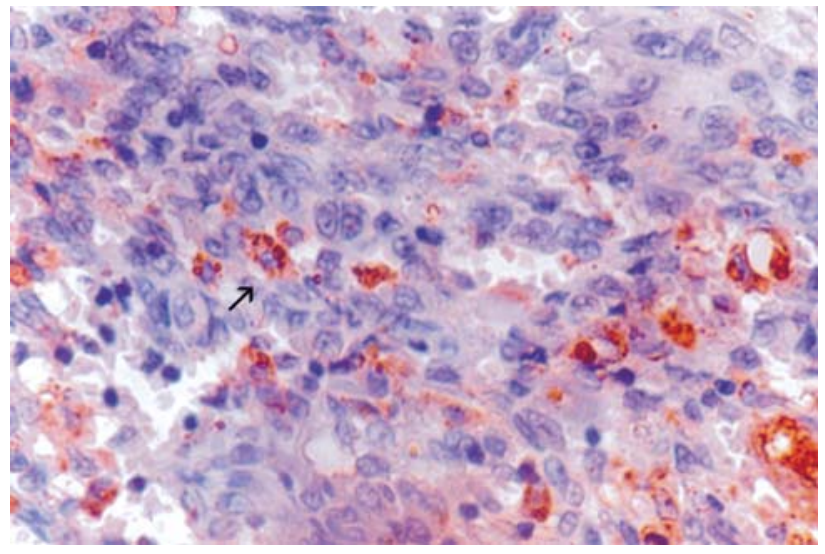

FIGURE 2 - Multinucleated giant cells and individual mononuclear cells CD68 positive in giant cell tumor of long bones (arrow) (SABC - 400x)

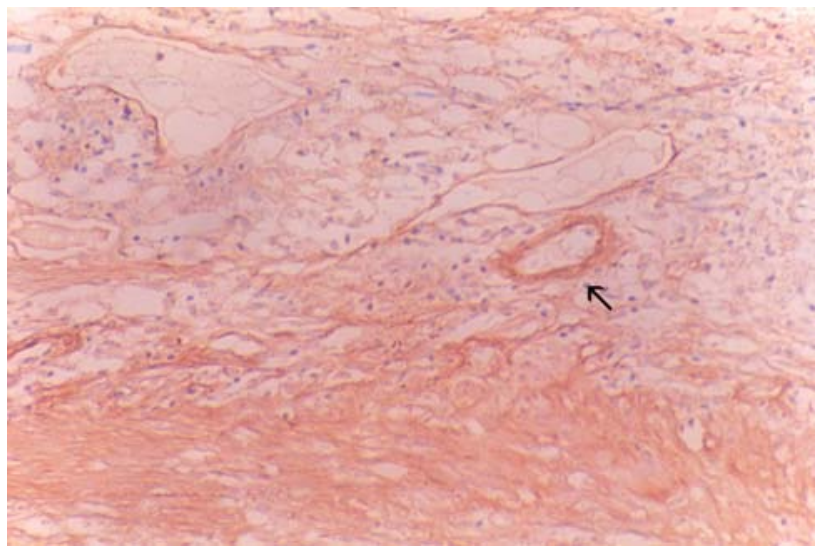

FIGURE 4 - Fibronectin immunoreactivity in giant cell tumor of long bones. Reticulate/fibrillar organization pattern and positive staining around the basement membrane of blood vessels (arrow) (SABC - 100x)

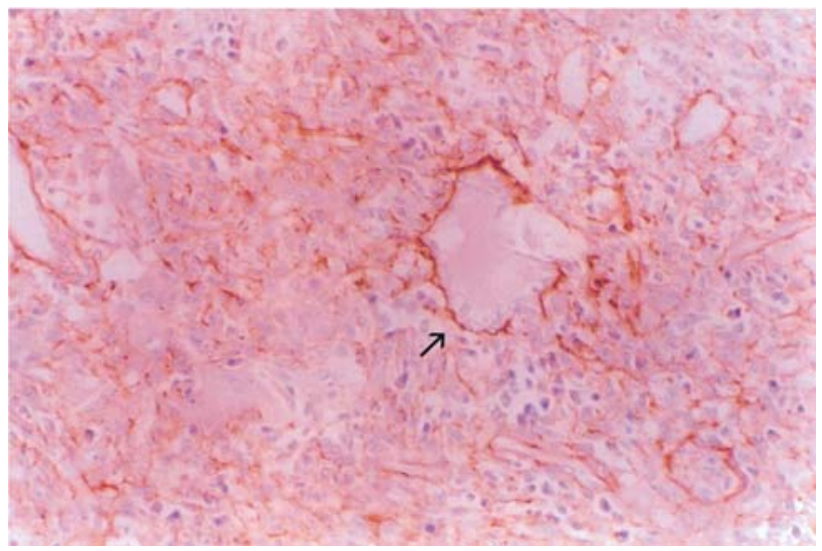

FIGURE 6 - Tenascin immunoreactivity in giant cell tumor of long bones. Reticulate organization pattern and positive staining around the basement membrane of blood vessels (arrow) (SABC - 200x) 
emphasize that since CGCG and GCT occur in different sites, it is difficult to compare accurately their biological evolution. Nevertheless, Souza, et al. ${ }^{21}$ (1999) suggest that CGCG and GCT could represent variants of the same disease.

CD68 monocyte-macrophage lineage marker has been often used in the investigation of giant cells. Our results demonstrated positive reactivity of many mononuclear cells and most of multinucleated giant cells to CD68 in both lesions studied, suggesting the existence of a histiocyte/ macrophage origin for some of the cellular components of CGCG and GCT, as shown by Carvalho, et al. ${ }^{6}$ (1995), Masui, et al. ${ }^{16}$ (1998), O'Malley, et al. ${ }^{19}(1997)$ and Werner $^{28}(2006)$.

In addition, $\operatorname{Werner}^{28}$ (2006) and Wülling, et al. ${ }^{30}$ (2001) emphasize that mononucleated histiocytic cells and multinucleated giant cells expressing CD68 antigen are recruited secondarily and do not constitute the actual neoplastic cell population in GCT. According to these authors, the proliferatively active neoplastic tumor cells,

TABLE 1- Fibronectin expression intensity, distribution and staining pattern in interstitial extracellular matrix of the central giant cell granulomas of the jaws

\begin{tabular}{lccl}
\hline $\begin{array}{c}\text { Case } \\
\text { Expression } \\
\text { intensity }\end{array}$ & $\begin{array}{c}\text { Distribution } \\
\text { Pattern }\end{array}$ & Staining \\
\hline 1 & ++ & uniform & Reticulate \\
2 & ++ & uniform & Fibrillar \\
3 & + & uniform & Fibrillar \\
4 & ++ & uniform & reticulate/ fibrillar \\
5 & ++ & uniform & reticulate/ fibrillar \\
6 & ++ & uniform & reticulate/ fibrillar \\
7 & ++ & uniform & reticulate/ fibrillar \\
8 & ++ & Uniform & Fibrillar \\
\hline
\end{tabular}

Source: Postgraduate Program in Oral Pathology of UFRN. ++ = intense immunoreactivity; + = weak immunoreactivity; - = negative immunoreactivity.

TABLE 2- Fibronectin expression intensity, distribution and staining pattern in interstitial extracellular matrix of the giant cell tumors of long bones

\begin{tabular}{lcll}
\hline $\begin{array}{c}\text { Case } \\
\text { intensity }\end{array}$ & $\begin{array}{c}\text { Distribution } \\
\text { Pattern }\end{array}$ & \multicolumn{1}{c}{ Staining } \\
\hline 1 & ++ & uniform & reticulate/ fibrillar \\
2 & ++ & uniform & reticulate/ fibrillar \\
3 & ++ & uniform & reticulate/fibrillar \\
4 & + & focal & fibrillar \\
5 & + & uniform & reticulate/fibrillar \\
6 & + & focal & reticulate \\
7 & ++ & uniform & reticulate/fibrillar \\
\hline
\end{tabular}

Source: Pathology and Cytology Laboratory, Aracaju, SE, Brazil. $++=$ intense immunoreactivity; $+=$ weak immunoreactivity; - = negative immunoreactivity. also described as GCT stromal cells, constitute varying portions of the tumoral tissue and do not belong to monocytic-histiocytic system.

Itonaga, et al. ${ }^{11}$ (2003), in a study performed on CGCG, identified the presence of cell subsets similar to those reported in GCT. These authors verified that mononuclear cells were constituted by two cell subsets, one revealing a macrophagic/ osteoclastic-precursor immunoprofile and another subset constituted by mesenchymal cells showing a immunoprofile towards a fibroblast/osteoblast lineage, expressing prolyl-4-hydroxylase and vimentin, being negative for macrophage associated antigens (CD11a, CD11b), leucocyte common antigen (LCA) and CD68. In addition, the conspicuous expression of proliferating cell nuclear antigen (PCNA) in the latter cell subset led Itonaga, et al. ${ }^{11}$ (2003) to suggest that the proliferative component of CGCG would be represented by a mesenchymal stromal cell which had the capacity to differentiate along fibroblast/

TABLE 3- Tenascin expression intensity, distribution and staining pattern in interstitial extracellular matrix of the central giant cell granulomas of the jaws

\begin{tabular}{lccc}
\hline $\begin{array}{c}\text { Case } \\
\text { Expression } \\
\text { intensity }\end{array}$ & $\begin{array}{c}\text { Distribution } \\
\text { Pattern }\end{array}$ & Staining \\
\hline 1 & ++ & focal & reticulate \\
2 & ++ & focal & reticulate \\
3 & ++ & uniform & reticulate \\
4 & ++ & uniform & reticulate/ fibrillar \\
5 & + & focal & fibrillar \\
6 & ++ & uniform & reticulate/ fibrillar \\
7 & ++ & focal & reticulate/ fibrillar \\
8 & ++ & uniform & reticulate/ fibrillar \\
\hline
\end{tabular}

Source: Post graduation Program in Oral Pathology of UFRN. $++=$ intense immunoreactivity; $+=$ weak immunoreactivity; - = negative immunoreactivity.

TABLE 4- Tenascin expression intensity, distribution and staining pattern in interstitial extracellular matrix of the giant cell tumors of long bones

\begin{tabular}{lccc}
\hline $\begin{array}{c}\text { Case } \\
\text { Expression } \\
\text { intensity }\end{array}$ & $\begin{array}{c}\text { Distribution } \\
\text { Pattern }\end{array}$ & Staining \\
\hline 1 & ++ & uniform & reticulate \\
2 & ++ & uniform & reticulate/ fibrillar \\
3 & ++ & uniform & reticulate/ fibrillar \\
4 & ++ & uniform & reticulate/ fibrillar \\
5 & ++ & uniform & reticulate \\
6 & ++ & uniform & reticulate \\
7 & ++ & uniform & reticulate/ fibrillar \\
\hline
\end{tabular}

Source: Pathology and Cytology Laboratory, Aracaju, SE, Brazil. ++ = intense immunoreactivity; + = weak immunoreactivity; - = negative immunoreactivity. 
osteoblast lines.

Accordingly, Liu, et al. ${ }^{15}$ (2003) verified the expression of vacuolar $\mathrm{H}^{+}$-ATPase (V-ATPase), carbonic anhydrase II (CA II), cathepsin K, MMP-9 and tartarate-resistant acid phosphatase (TRAP) in multinucleated giant cell of CGCG, thus confirming the characteristics of an osteoclastic phenotype. Moreover, the authors observed strong expression of receptor activator of NF-kB ligand (RANKL), an important cytokine necessary and sufficient for osteoclastogenesis, by the spindle stromal cells and the expression of receptor activator of NF-kB (RANK) by round mononuclear and multinucleated giant cells. Therefore, Liu, et al. ${ }^{15}$ (2003) summarizes that stromal spindle cells of CGCG induce the bone-resorption function by secreting RANKL which interacts with its receptor in multinucleated giant cells, similar to the normal situation of mature osteoclasts.

The study performed by Wang, et al. ${ }^{27}$ (2006) described strong similarities of the osteoclastogenesis process in lesions containing multinucleated giant cells. These authors, analyzing the mRNA and protein levels of c-Src, a molecule involved in an important signaling pathway downstream of RANK, verified the expression of this component both in CGCG of the jaws and GCT of long bones with no significant differences. These results led Wang, et al. ${ }^{27}$ (2006) to suggest that c-Src may be a common signaling cascade during osteoclastogenesis in CGCG and GCT, regardless the location either in the jaws or long bones.

Only few studies analyzing the constitution of the extracellular matrix of CGCG and GCT have been performed. Within this subject, Ueda, et al. ${ }^{25}$ (1996), studying components of vascular basement membranes and matrix metalloproteinases in GCT of long bones, reported important findings. These authors verified weak or absence of expression of collagen IV and laminin in vascular basement membranes close to multinucleated giant cells revealing strong expression of MMP-9. In addition, Ueda, et al. ${ }^{25}$ (1996) described a reduction of MMP-9 level in multinucleated giant cells present within vessels, suggesting that MMP-9 may be consumed during migration of tumor cells through the blood vessel basement membrane. Therefore, these authors implied that MMP-9 is an important protease for vascular invasion of multinucleated giant cells in GCT.

Kumta, et al. ${ }^{14}$ (2003), analyzing the expression of vascular endothelial growth factor (VEGF) and MMP-9 in many osseous lesions, correlating to radiographic staging of osteolytic destruction, observed that lesions in advanced stages and recurrent lesions, including the GCT, revealed higher expression of MMP-9 and VEGF. According to Kumta, et al. ${ }^{14}$ (2003) the level of MMP-9 and VEGF expression may provide some prognostic indication of biologically aggressive behavior and local disease recurrence in osteolytic lesion affecting bone.

Interesting findings in relation to VEGF expression have also been observed in CGCG. Vered, et al. ${ }^{26}$ (2006) studied 41 cases of CGCG for the immunoreactivity to VEGF and basic fibroblastic growth factor (bFGF) in relation to angiogenic activity, assessed by a stereological method for measuring microvascular volume. Despite the high levels of immunoreactivity to VEGF and bFGF in the lesions, found prominently in mononuclear stromal cells and multinucleated giant cells, it was observed a low mean microvascular volume. Therefore, Vered, et al. ${ }^{26}$ (2006) state that VEGF and bFGF expression could be related to stimulation of osteoclastogenesis in CGCG, suggesting that high levels of VEGF- and bFGF-producing cells in a CGCG would be related to a more aggressive biological behavior.

Fibronectin is a glycoprotein of the extracellular matrix and plasma protein that has function in cell adhesion and spreading. It is found in most body fluids, connective tissues, granulation tissues and basement membranes ${ }^{1,4}$. This protein plays several biological functions and an important role in neoplastic development and other pathological processes, including those that occur in oral cavity ${ }^{1,2,3,5}$.

Fibronectins may be associated with invasion and metastasis. Therefore, fibronectin variants could be used as possible prognostic factor ${ }^{12}$. Our study showed that fibronectin immunoreactivity was readily detectable in both giant cell lesions. Staining was exclusively stromal, with no evidence of an intracellular positive reaction. The variable staining intensity observed between CGCG of the jaws and GCT of long bones was not significant to be used as diagnostic differential factor.

In the present study, fibronectin reticulate/fibrillar was the most common pattern of organization in the evaluated lesions, followed by single fibrillar and reticulate organized patterns. We have hypothesized that the fibronectin different organization patterns seem non-significant, as the prominence of the mixed pattern revealed that fibronectin can be presented under the reticulate and fibrillar aspects in a single case.

Although fibronectin reticular organized pattern had been associated with the presence of inflammatory cells ${ }^{18,22}$, our findings do not confirm this fact because this pattern type could be detected in some lesions that did not present inflammatory process. The fibrillar organized pattern of fibronectin staining, following the collagen fibers, in CGCG of the jaws, described in this study is consistent with previous study carried out by $\operatorname{Cardoso}^{5}$ (2000).

Tenascin is a glycoprotein of the extracellular matrix expressed in epithelial-mesenchymal interactions during embryogenesis and tumorigenesis of several tissues ${ }^{7}$ that plays an important role as a molecular mediator in proliferation and progression in neoplastic processes ${ }^{24}$.

In this study, we observed intense immunoreactivity of tenascin within individual specimens of GCT of long bones and CGCG of the jaws and marked variation in its spatial distribution, presenting focal organization in 4 cases of CGCG of the jaws, whereas uniform distribution was detected in all cases of GCT of the long bones.

The loose connective tissue between the fascicles presenting inflammatory infiltrate has been associated with increased tenascin expression ${ }^{24}$. Like Cardoso ${ }^{5}$ (2000) and Mighell, et al. ${ }^{17}$ (1996), we also observed no association between areas where inflammatory cells were present and tenascin immunoreactivity enhancement. 
The findings of this study showed predominant reticulate organized pattern of the tenascin in most of the specimens of both of the analyzed lesions. In some cases, it was observed as a single reticular pattern, but there were cases revealing association with the fibrillar pattern. The fibrillar pattern isolated was identified following the collagen fibers, similar to that reported by $\operatorname{Cardoso}^{5}$ (2000) and Tarquínio $^{22}$ (1999). In this study, tenascin immunoreactivity revealed similarities between both giant cell lesions studied.

\section{CONCLUSIONS}

Despite the low number of tissue specimens of CGCG and GCT evaluated, that was a methodological limitation, the findings of the present study revealed immunohistochemical similarities between CGCG of the jaws and GCT of long bones, supporting the observation that sometimes these lesions are indistinguishable. Further research is needed to clarify the pathogenesis and nature of these giant cell lesions and other markers have to be investigated in order to answer the question of whether these lesions represent the development of a single pathologic process or not.

\section{REFERENCES}

1- Abrahamson DR. Recent studies on the structure and pathology of basement membranes. J Pathol. 1986;149:257-78.

2- Alberts B, Bray D, Lewis J. Biologia molecular da célula. Porto Alegre: Artmed; 1997

3- Andrade MC, Pereira Pinto L, Souza LB. Expressão imunohistoquímica do CD44v6, fibronectina e tenascina em mucosa oral normal, hiperplasia fibro-epitelial e displasia epitelial. RPG Rev Posgrad. 2003;10(1):59-69.

4- Armstrong PB, Armstrong MT. Intercellular invasion and the organization stability of tissues: a role for fibronectin. Biochim Biophys Acta. 2000;1470(2):9-20.

5- Cardoso LBQ. Expressão imuno-histoquímica de componentes da matriz extracelular (colágeno IV, tenascina-C e fibronectina) em lesões central e periférica de células gigantes: estudo comparativo [tese]. Natal (RN): Faculdade de Odontologia, Universidade Federal do Rio Grande do Norte; 2000.

6- Carvalho YR, Loyola AM, Gomez RS, Araújo VC. Peripheral giant cell granuloma. An immunohistochemical and ultrastructural study. Oral Dis. $1995 ; 1(1): 20-5$

7- Chiquet-Ehrismann R, Hagios C, Schenk S. The complexity in regulating the expression of tenascin. Bioessays. 1995;17(10):8738 .

8- Gouin F, Grimaud E, Redini F, Moreau A, Passuti N, Heymann D. Metatarsal giant cell tumor and giant cell reparative granuloma are similar entities. Clin Orthop Relat Res. 2003,416:278-84.

9- Grill V, Sandrucci MA, Basa M, Di Lenarda R, Dorigo E, Narducci $\mathrm{P}$, et al. The influence of dental metal alloys on cell proliferation and fibronectin arrangement in human fibroblast cultures. Arch Oral Biol. 1997;42(9):641-7.
10 - Holness CL, Simmons DL. Molecular cloning of CD68, a human macrophage marker related to lysosomal glycoproteins. Blood. 1993;81(6):1607-13.

11 - Itonaga I, Hussein I, Kudo O, Sabokbar A, Watt-Smith S, Ferguson $\mathrm{D}$, et al. Cellular mechanisms of osteoclast formation and lacunar resorption in giant cell granuloma of the jaw. J Oral Pathol Med. $2003 ; 32: 224-31$

12-Kosmehl H, Berndt A, Katenkamp D. Molecular variants of fibronectin and laminin: structure, physiological occurrence and histopathological aspects. Virchows Arch. 1996;429:311-22.

13- Kruse-Lösler B, Diallo R, Gaertner C, Mishcke KL, Joos U, Kleinheinz J. Central giant cell granuloma of the jaws: a clinical, radiologic and histopathologic study of 26 cases. Oral Surg Oral Med Oral Pathol Oral Radiol Endod. 2006;101:346-54.

14- Kumta SM, Huang L, Cheng YY, Chow LT, Lee KM, Zheng MH. Expression of VEGF and MMP-9 in giant cell tumor of bone and other osteolytic lesions. Life Sci. 2003;73:1427-36.

15- Liu B, Yu SF, Li TJ. Multinucleated giant cells in various forms of giant cell containing lesions of the jaws express features of osteoclasts. J Oral Pathol Med. 2003;32:367-75.

16- Masui F, Ushigome S, Fuji K. Giant cell tumor of bone: an immunohistochemical comparative study. Pathol Int. 1998;48(5):355-61.

17- Mighell AJ, Robinson PA, Hume WJ. Immunolocalisation of tenascin-C in focal reactive overgrowths of oral mucosa. J Oral Pathol Med. 1996;25:163-9.

18 - Oliveira MDC, Miranda JL, Amorim RF, Souza LB, Freitas RA. Tenascin and fibronectin expression in odontogenic cysts. J Oral Pathol Med. 2004;33:354-9.

19- O’Malley M, Pogrel MA, Stewart JC, Silva RG, Regezi JA. Central giant cell granulomas of the jaws: phenotype and proliferationassociated markers. J Oral Pathol Med. 1997;26:159-63.

20- Povýsil C, Bennett R, Povysilova V. CD68 positive of the socalled meconium corpuscles in human foetal intestine. Cesk Patol. 2001;37:7-9.

21-Souza PE, Paim JF, Carvalhais JN, Gomez RS . Immunohistochemical expression of p53, MDM2, Ki67 and PCNA in central giant cell granuloma and giant cell tumor. J Oral Pathol Med. 1999;28:54-8.

22- Tarquínio SBC. Estudo de componentes da matriz extracelular no líquen plano, penfigóide benigno da mucosa e pênfigo vulgar [tese]. São Paulo (SP): Faculdade de Odontologia, Universidade de São Paulo; 1999

23 - Tiffee JC, Aufdemorte TB. Markers for macrophage and osteoclast lineages in giant cell lesions of the oral cavity. J Oral Maxillofac Surg. 1997;55:1108-12.

24- Tiitta O, Happonen RP, Virtanen I, Luomanen M. Distribution of tenascin in oral premalignant lesions and squamous cell carcinoma. J Oral Pathol Med. 1994;23:445-50.

25 - Ueda Y, Imai K, Tsuchiya H, Fujimoto N, Nakanishi I, Katsuda S, et al. Matrix metalloproteinase 9 (gelatinase B) is expressed in multinucleated giant cells of human giant cell tumor of bone and is associated with vascular invasion. Am J Pathol. 1996;148(2):61122 . 
26- Vered M, Buchner A, Dayan D. Giant cell granuloma of the jaw bones: a proliferative vascular lesion? Immunohistochemical study with vascular endothelial growth factor and basic fibroblastic growth factor. J Oral Pathol Med. 2006;35(10):613-9.

27- Wang C, Song Y, Peng B, Fan M, Li J, Zhu S, et al. Expression of c-Src and comparison of cytologic features in cherubism, central giant cell granuloma and giant cell tumors. Oncol Rep. 2006;15:58994.

28 - Werner M. Giant cell tumour of bone: morphological, biological and histogenetical aspects. Int Orthop. 2006;30:484-9.

29- Whitaker SB, Waldron CA. Central giant cell lesions of the jaws: a clinical, radiologic and histopathologic study. Oral Surg Oral Med Oral Pathol. 1993;75:199-208.

30- Wülling M, Engels C, Jesse N, Werner M, Delling G, Kaiser E. The nature of giant cell tumor of bone. J Cancer Res Clin Oncol. $2001 ; 127: 467-74$ 